\title{
Shelf Life Studies of Three Wasabi Flavoured Sauces
}

\author{
Tamanna Sultana $^{a *}$, G. P. Savage ${ }^{\mathrm{b}}$, N. G. Porterc, D. L. McNeil ${ }^{\mathrm{d}}$ and J. R. Sedcole \\ ${ }^{a}$ Applied Chemistry and Chemical Technology,University of Dhaka, Bangladesh; ${ }^{b}$ Food Group, Agriculture and \\ Life Sciences Division, Lincoln University, New Zealand; 'New Zealand Institute for Crop \& Food Research Ltd, \\ Christchurch, New Zealand; ${ }^{d}$ Director TIAR, Chair of Agricultural Science, University of Tasmania, Australia \\ and ${ }^{e}$ Applied Management and Computing Division, Lincoln University, Canterbury, New Zealand.
}

\begin{abstract}
Isothiocyanates (ITCs) contained in purees extracted from wasabi (Wasabia japonica (Miq) Matsum) can be used to manufacture a range of interesting spicy foods. In New Zealand, local manufacturers are showing interest in producing various forms of processed wasabi based sauces. However, isothiocyanates have been shown to degrade quickly in some situations. Therefore, in this study, the stability of allyl ITC was investigated in three wasabi flavoured products stored at four different temperatures $\left(4,10,20\right.$ and $\left.30^{\circ} \mathrm{C}\right)$ for 22 weeks. Two creamy (mayonnaise and tartare) sauces and a non-creamy sauce were prepared from an original recipe and flavoured with a known volume of "wasabi oil". Two types of pouches (clear and metallic plastic) were used to store each product and allyl ITC content was measured in the stored sauces at two week intervals. The initial level of allyl ITC found in mayonnaise, tartare and smoky tomato sauces were 415.3, 411.4 and $144.7 \mathrm{mg} / \mathrm{kg}$ respectively, prior to storage. Temperature showed a strong influence in reducing allyl ITC $(P=0.005$ to $<0.001)$ but no significant effect was identified for the two types of packets used. The non-creamy smoky tomato sauce was very unstable at $10^{\circ} \mathrm{C}$ or higher temperatures and the allyl ITC contents reduced rapidly with increasing storage temperatures. For instance, at $30^{\circ} \mathrm{C}$, a $66 \%$ loss occurred by week 2 and a $90 \%$ loss occurred by week 6 in the smoky tomato sauce. However, mayonnaise and tartare sauces had a shelf life of 8 to 9 weeks with only a marginal reduction in allyl ITC ( $2 \%$ overall) at all the stored temperatures $\left(4-30^{\circ} \mathrm{C}\right)$. These creamy sauces were characterized by a sudden fall in 10 weeks ending in a 69-70\% loss of allyl ITC at 22 weeks. No microbial growth occurred in any of the sauces stored at any of the temperatures during the course of this storage experiment though very small change of colour was noticed for the sauces when stored at $30^{\circ} \mathrm{C}$.
\end{abstract}

Keywords: Wasabia japonica, Allyl isothiocyanate, Mayonnaise, Temperature, Storage time, Shelf-life, CIE L

\section{Introduction}

Wasabi (Wasabia japonica (Miq.) Matsum) has been grown in New Zealand primarily to export as minimally processed intact plant materials to Japan and also to sell as raw material for the local food industries. Grated wasabi rhizome is a traditional condiment in the Japanese diet, and is prepared fresh before each meal. To meet the increased demand for wasabi flavourings in western cuisine, as well as in Japanese cuisine, manufacture of processed wasabi products based on New Zealand grown wasabi is of considerable interest to local industries. The hot spicy flavour of wasabi comes from the isothiocyanates (ITCs), which are a group of volatile and heat labile sulphur compounds. ITCs are evolved from the precursor glucosinolates in plant tissues when the tissues are disrupted by any means (e.g. cutting, grating, chewing). Allyl ITC is the principal component in wasabi (Masuda et al., 1996; Sultana et al., 2002; Sultana et al., 2003) and it

*Corresponding Author, Email: musawvir@yahoo.com.au possesses strong pungent mustard like odour (Sultana et al., 2000). Because of the volatile nature of ITCs a common problem for processors is the stability of ITCs when wasabi flavoured sauces are stored at different temperatures. Recent investigations have shown that loss of ITCs may occur at higher temperatures due to evaporation or by thermal degradation to other compounds. For example, synthetic allyl ITC was found to be unstable in water at $37^{\circ} \mathrm{C}$ as it gradually degrades to a non-volatile compound, N, N-diallyl-thiourea (Chen and Ho, 1998). Under cooking conditions $\left(100^{\circ} \mathrm{C}\right)$, allyl ITC decomposed to aliphatic and cyclic sulphur-containing volatile compounds, which possessed a garlic-like flavour with only $38 \%$ of the original allyl ITC remaining after an hour of heating (Chen and Ho, 1998). Research on a variety of foods containing ITCs showed that heating at higher temperatures (between $100-110^{\circ} \mathrm{C}$ ) for $30-60$ minutes caused $60 \%$ loss of the original ITC concentration in crambe 
(Crambe abyssinica) cake (Yong-Gang et al., 1994). Processing at higher temperatures (between 170 to $180^{\circ} \mathrm{C}$ ) caused a rapid decomposition of allyl ITC in wasabi (Sekiyama et al., 1994) and ITCs disappeared quickly from cabbage roots autoclaved at $120^{\circ} \mathrm{C}$ for 20 minutes. Heating cabbage extract at $48^{\circ} \mathrm{C}$ for 60 minutes (Vierheilig and Ocampo, 1990) also caused a rapid loss of ITCs. Kojima and Nakano (1980) found that even if wasabi powder was stored in airtight containers, ITC levels decreased over time, and when the powder contained higher levels of moisture the losses increased. Hydrolysates of wasabi powder showed a reduced level of ITC when stored at increasing temperatures (5 to $30^{\circ} \mathrm{C}$ ). However, ITCs were stable in the hydrolysates when stored at $-15^{\circ} \mathrm{C}$. About half of the concentration of different ITCs were lost after four weeks storage of wasabi powder in sealed vessels at $30^{\circ} \mathrm{C}$. Iso-propyl ITC was even less stable, with half the original amount lost after one week (Kojima et al., 1982). Tseng et al., (1986) suggested that hot air drying at $45^{\circ} \mathrm{C}$ (resulting in $3363 \mathrm{mg}$ allyl ITC/kg dry wt) is a good method for preparing wasabi powder compared with freeze-drying (resulting in $3030 \mathrm{mg}$ allyl ITC / kg dry wt) and sun drying (only $357 \mathrm{mg} / \mathrm{kg}$ dry wt) methods. Similarly, from a study on horseradish roots processed into a dried product (Sahasrabubhe and Mullin, 1980), it is recommended that processing must carried out on the cleaned roots immediately after dicing or crushing, at a temperature below $65^{\circ} \mathrm{C}$. These conditions retained the viability of enzymes forming the ITCs and, consequently, resulted in maximal yields of product with the desired flavour intensity and acceptable odour. Depree and Savage (1996) reported on the potential loss of ITCs during a shelf life study on wasabiITC containing sauces. They stated that the level of ITC fell $15 \%$ in wasabi mayonnaise stored at 4 to $20^{\circ} \mathrm{C}$ for 14 days and $25 \%$ in samples stored at $30^{\circ} \mathrm{C}$. They also stated that, in mayonnaise, ITCs appeared to decrease with time, whereas in oil $99 \%$ of the original level of ITC was found after 57 days at $4{ }^{\mathrm{O}} \mathrm{C}$, highlighting the effect of water and other ingredients in the storage of mayonnaise.

It is important for processors to understand the dynamics of ITC stability under different storage conditions in order to retain quality and flavour in their products. However, there is little published information in English on ITC behaviour during storage. Half-life studies of products stored at different temperatures are essential before a product can be marketed with confidence. Therefore, the purpose of this study was to investigate the shelf life of ITCs from different types of sauces containing various amounts of "wasabi oil" stored at four different temperatures in two different types of packaging. The overall information gained from this study will provide valuable information for processors on how to store their product and retain its full commercial value.

\section{Materials and Methods}

\section{Experimental design}

The design of the experiment was a $2 \mathrm{X} 3 \mathrm{X} 4 \mathrm{X} 12$ (package, sauce, temperature and time period) factorial in a single replication with a pseudo replication using two extractions.

\section{Preparation of wasabi extract in oil "wasabi oil"}

Fresh, locally grown wasabi rhizomes were harvested and minced to allow the myrosinase enzyme in the plant tissue to degrade the stored glucosinolates. The volatile ITCs were extracted into canola oil and stored at $-4^{\mathrm{O}} \mathrm{C}$ in sealed plastic containers until required for incorporation into sauces. The ITC concentration in the "wasabi oil" was $4400 \mathrm{mg}$ total ITC/ kg of oil.

\section{Preparation of sauces}

Two types of wasabi sauces, creamy and non-creamy, were prepared from the standard commercial recipes in a research and development laboratory of a local food business in Christchurch, New Zealand. Two different creamy white sauces were made using 11\% "wasabi oil": A) Original mayonnaise, B) Tartare sauce, and one non-creamy sauce C) Smoky tomato sauce, based on a high dry matter tomato paste using 6.44\% "wasabi oil".

The creamy sauce (i.e. mayonnaise) was prepared from a mixture of egg yolk, vinegar, salt, sugar, starch, oil and mustard powder. Mayonnaise typically contains $70-80 \%$ fat; however, the tartare sauce and original mayonnaise in this study contained 28.4 and $30.4 \%$ fat and $60 \%$ and 59\% water, respectively. Mayonnaise is an oil-in-water emulsion. An emulsion was prepared by first mixing the eggs, vinegar, salt, sugar, starch and mustard together at room temperature and then the oil was slowly blended without heating into the aqueous phase. The smoky tomato sauce contained no egg yolk but contained tomato paste and garlic, onion and pepper, in addition to vinegar, salt, sugar, starch and oil. The chopped onion was fried in canola oil for 5 minutes at $90^{\circ} \mathrm{C}$ and then blended thoroughly with the other spices and vinegar at room temperature. Oil was slowly blended in an $\mathrm{N}$ creamer 46 (National Starch and Chemical NZ Ltd, Greenmount, Auckland, New Zealand) and then the two groups of ingredients were mixed and blended together using a kitchen blender (Breville, model 0126 HB 80, Spain). The oil: water ratio in the smoky tomato sauce was 6.4:68. The bulk prepared "wasabi oil" was added to all three types of the sauces. No commercial preservative or colour was added to these products. 
Two types of pouches were used in this experiment: I) Clear plastic: transparent poly-vinyl chloride and II) Metal/plastic laminate: transparent poly-vinyl chloride laminated with aluminium on the outside (more oxygen impermeable, would store better if the pouches were stored in the light). The 200 g ready-made pouches $(149.5 \mathrm{~mm}$ x $109.2 \mathrm{~mm}$ x $0.11 \mathrm{~mm}$ ) with sealed screw stoppers were purchased from a local manufacturer (Caspak Ltd., Christchurch). $50 \mathrm{~g}$ of each sauce was accurately weighed and poured into each pouch through the opened top. After filling, the pouch with sauce in a pouch excess air was removed by squeezing the pouch followed by sealing the top edges by heat pressing (Impulse Auto Sealer, Marker Developments, Glenfield, Auckland, New Zealand). The filled and sealed pouches containing smoky tomato sauce received a heat treatment $\left(90^{\circ} \mathrm{C}\right.$ for 1 hour) in a water bath as a final step to sterilize.

The three types of sauce were stored in temperature controlled incubators set at $4 \pm 2^{\circ} \mathrm{C}, 10 \pm 2^{\circ} \mathrm{C}, 20 \pm 2^{\circ} \mathrm{C}$ and 30 $\pm 2^{\mathrm{O}} \mathrm{C}$ for 22 weeks. ITC analysis, colour measurement and microbiological tests were carried out at two week intervals starting from the day of manufacture i.e. zero day of storage $(0,2,4,6,8,10,12,14,16,18,20,22$ weeks $)$. A fresh pouch was opened at each storage time for each storage temperature, sauce and package type.

\section{Isothiocyanate analysis}

\section{Extraction}

$2 \mathrm{~g}$ of sauce from each treatment combination (temperature, sauce, packet and time) was weighed separately into a $40 \mathrm{ml}$ Beckman plastic centrifuge tube (Beckman, Palo Alto, CA, USA) containing $5 \mathrm{ml}$ of methanol (Hipersolv grade, BDH Laboratory Supplies, Poole UK). The samples were mixed in a Hybaid oven (MK II, Hybaid Ltd, Ashford, UK) at $20^{\circ} \mathrm{C}$ for 2 hours and then separated from the paste by centrifugation (121,000 x g, $20^{\circ} \mathrm{C}$ for 8 minutes) in a Beckman J2 M1 centrifuge. The methanol extract was stored at $-20^{\circ} \mathrm{C}$ prior to GC analysis of the ITCs. Two replications were used for extraction of ITCs from each sample.

\section{Gas chromatography analysis}

Samples $(1 \mu \mathrm{l})$ of methanol extract were injected (splitless mode) onto a Hewlett-Packard (HP) INNOwax capillary column (30 m, $0.25 \mathrm{~mm}$, i.d. and $0.25 \mu \mathrm{m}$ film thickness) in a HP 6890 gas chromatograph fitted with a flame photometric detector (FPD), and a HP 6890 automatic sampler (Hewlett Packard, Palo Alto, CA, USA). The inlet and detector temperatures were $160^{\circ} \mathrm{C}$ and $250^{\circ} \mathrm{C}$, respectively. Hydrogen was used as a carrier gas at an inlet pressure of $85.9 \mathrm{Kpa}$, flow rate of $2.3 \mathrm{ml} / \mathrm{min}$. Separations were performed under the following temperature program: 50 to $100^{\circ} \mathrm{C}$ at $5^{\circ} \mathrm{C} / \mathrm{min}$, 100 to $240^{\circ} \mathrm{C}$ at $10^{\circ} \mathrm{C} / \mathrm{min}$, then held at $240^{\circ} \mathrm{C}$ for 5 minutes. Peak areas were recorded and calculated using HP Chemstation software (Version A.06.03). The butyl ITC (Eastman Organic Chemical, Rochester, NY, USA) calibration curve was used to quantify the levels of each ITC.

\section{Gas chromatography-mass spectroscopy (GCMS)}

Allyl ITC was identified by GCMS on a Carlo Erba MFC500 gas chromatograph (split ratio 30:1, HP DB5MS 30 m, 0.25 $\mathrm{mm}$ i.d., $0.25 \mu \mathrm{m}$ film column, He carrier gas flow $2 \mathrm{ml}$ /min; Carlo Erba, Milan, Italy) and a Kratos MS80RFA mass spectrometer (4 kv accelerating potential, $70 \mathrm{ev}$ ionization energy, source temperature $250^{\circ} \mathrm{C}$, magnet scan $500-30$ AMU; Kratos, Manchester, UK). The identity of allyl ITC was confirmed by comparing spectra with published spectra from Kjoer et al. (1963) and Wiley's database.

\section{Colour measurement}

Colour measurements, using a Minolta Chroma Meter CR200 (Minolta Camera Co. Ltd., Osaka, Japan) were taken on the fresh and stored samples. Each sample was poured into a round petri dish and the colour was measured three times. The Chroma Meter consisted of an $8 \mathrm{~mm}$ diameter measuring area and diffuse illumination $/ 0^{\mathrm{O}}$ viewing was used. The Minolta colorimeter read colours in three axes. The vertical axis $L^{*}$ measures the luminance factor of the colour and ranges from 0 (black) to 100 (white). Thus, $\mathrm{L}^{*}$ is equivalent to brightness, the lower the $\mathrm{L}^{*}$ the darker the test sample. The $\mathrm{a}^{*}$ axis represents the balance between magenta-red (+ $\left.a^{*}\right)$ and green $\left(-a^{*}\right)$, whereas, the $b^{*}$ axis represents the balance between yellow $\left(+b^{*}\right)$ and blue $\left(-b^{*}\right)$. The CIE $L^{*}, a^{*}$ and $b^{*}$ readings were calibrated against a standard white tile before each reading.

\section{Microbiological analysis}

Each sample was visually observed, for any growth of yeast and mould, on each day of ITC analysis and then sent to the microbiology laboratory in Hi-Tech Foods Ltd, Christchurch, New Zealand. An aerobic plate count was measured using standard food method by pouring $1 \mathrm{ml}$ of sauce into agar and then incubating for 48 hours at $35^{\circ} \mathrm{C}$. Bacterial colonies were counted using a colony counter (Gallenkamp, UK).

\section{Statistical analysis}

The derived coefficients from the logistic function were used as a variate in an analysis of variance (ANOVA) using the Genstat statistical package (2000) to study the effects of four treatments (storage temperature, packaging material, sauce 
type and time) and their interactions on the concentration of allyl ITC in the sauces. Significant and non-significant responses for the fitted coefficients are presented in Tables IIV. Graphical presentations were prepared (Fig. 1-4) based on the mean from the two packet types and from two extraction replicates using Sigmaplot graphics software (1999).

The effect of treatments (package, sauce and temperature) was obtained by fitting a time dependent curve to the data from which estimates of the coefficients of the fitted curve were obtained. The response was largely sigmoidal with the more extreme treatments causing the response to appear as exponential. This has been interpreted as a truncated logistic. The function with its parameters, is: $\mathrm{Y}=\mathrm{a}+\mathrm{c} /(1+\exp (\mathrm{b} *(\mathrm{t}-$ m))) where

$\mathrm{t}$ = time of storage;

$\mathrm{a}=$ lower asymptote;

$\mathrm{c}=$ the amount that the response falls, i.e. $\mathrm{a}+\mathrm{c}$ is the initial asymptote;

$\mathrm{b}=$ the rate coefficient, if this is constant between treatments then the differences between the treatments for the decline is due to the end values, rather than there being any intrinsic difference in the rate of decline.

$m=$ the point of inflexion. For the exponential curves, the point may be negative i.e. the point of inflexion may be reached before the measurement begins.

For the smoky tomato sauce deterioration set in quickly, especially when stored at higher temperatures, so the logistic function could not be fitted directly. Two approaches were taken to overcome this problem: one is to assume a value for c (65, see Table IV) based on the rest of the data and to fit the restricted function to the data for smoky tomato 10 and $20^{\circ} \mathrm{C}$ storage, and the other was to fit an exponential function $\left(\mathrm{Y}=\mathrm{a}-\mathrm{b}^{*} \exp \left\{\mathrm{c}^{*} \mathrm{t}\right\}\right)$ and to use appropriate estimates (from the smoky tomato data at $30^{\circ} \mathrm{C}$ ) for the analysis.

\section{Results and Discussion}

\section{Allyl ITC in sauces at the start of storage (day zero)}

The allyl ITC found on the day of manufacture in the original mayonnaise, tartare and smoky tomato sauces were respectively $415.3,411.4$ and $144.7 \mathrm{mg} / \mathrm{kg}$ of fresh weight of sauce. These were $86 \%, 85 \%$ and $51 \%$ of the originally added ITCs in the "wasabi oil" in original mayonnaise, tartare and smoky tomato sauce, respectively.
Table I. The effect of packaging material on the coefficient of fitted curve

\begin{tabular}{|c|c|c|c|c|}
\hline \multirow{2}{*}{$\begin{array}{l}\text { Coefficient } \\
\text { of the } \\
\text { fitted } \\
\text { curve }\end{array}$} & \multicolumn{2}{|c|}{$\begin{array}{l}\text { Packaging material } \\
\text { used for storage }\end{array}$} & \multirow[b]{2}{*}{ SEM } & \multirow[b]{2}{*}{$\begin{array}{c}P \\
\text { value }\end{array}$} \\
\hline & $\begin{array}{l}\text { Clear } \\
\text { plastic }\end{array}$ & $\begin{array}{c}\text { Metallic/ } \\
\text { Clear } \\
\text { plastic } \\
\text { laminate }\end{array}$ & & \\
\hline b & -1.574 & -1.573 & 0.098 & 0.99 \\
\hline $\mathrm{m}$ & 8.78 & 8.57 & 0.16 & 0.39 \\
\hline C & 225.5 & 227.1 & 2.6 & 0.67 \\
\hline $\mathrm{a}$ & 100.0 & 95.8 & 2.0 & 0.16 \\
\hline
\end{tabular}

$\mathrm{SEM}=$ Standard error of means

\section{Effect of packaging materials}

There was no significant difference ( $P=0.16$ - 0.99) of the curve coefficients (b, $\mathrm{m}, \mathrm{c}$ and a) between the two packaging materials used for storing the sauces (Table I). As a consequence, attention should be directed to any significant variations observed for curve coefficients in the other treatments combinations to find out the effect of the treatments.

\section{The decay pattern of allyl ITC with storage treatment}

The mean value of allyl ITC from the two types of packets has been used to plot points in Figures 1 to 4, since no significant difference in allyl ITC level observed between the two packaging materials used for storing the sauces.

The percentage loss of allyl ITC in the sauces is plotted against storage times separately for the four different storage temperatures $\left(4,10,20\right.$ and $\left.30^{\circ} \mathrm{C}\right)$ in Figures 1 to 4 , which show how the levels were affected by the treatments (i.e. temperature, sauces and time). Between the two types of creamy (original mayonnaise and tartare sauces) and noncreamy (smoky tomato) sauces a different decay pattern was observed when stored at $\geq 10^{\circ} \mathrm{C}$. The smoky tomato sauce started showing this difference from the two creamy sauces from 2 weeks. In the creamy sauces after 10 weeks the rapid $\%$ loss of allyl ITC brought the final levels much closer. The smoky tomato sauce contained a lower level of allyl ITC ( $144.7 \mathrm{mg} / \mathrm{kg}$ of sauce or $51 \%$ of the initial level) from manufacture compared to other creamy sauces ( $415.3 \pm 0.98$ and $411.4 \pm 0.20 \mathrm{mg}$ of allyl ITC $/ \mathrm{kg}$ ). The smoky tomato sauce showed an exponential decline with respect to storage time for $10^{\circ} \mathrm{C}$ or higher temperatures (Figures 2-4) and the deterioration began sooner and was more rapid at higher temperatures. For instance, at $30^{\circ} \mathrm{C}$ storage a $66 \%$ loss occurred by 2 weeks in smoky tomato followed by a $90 \%$ loss in 6 weeks 


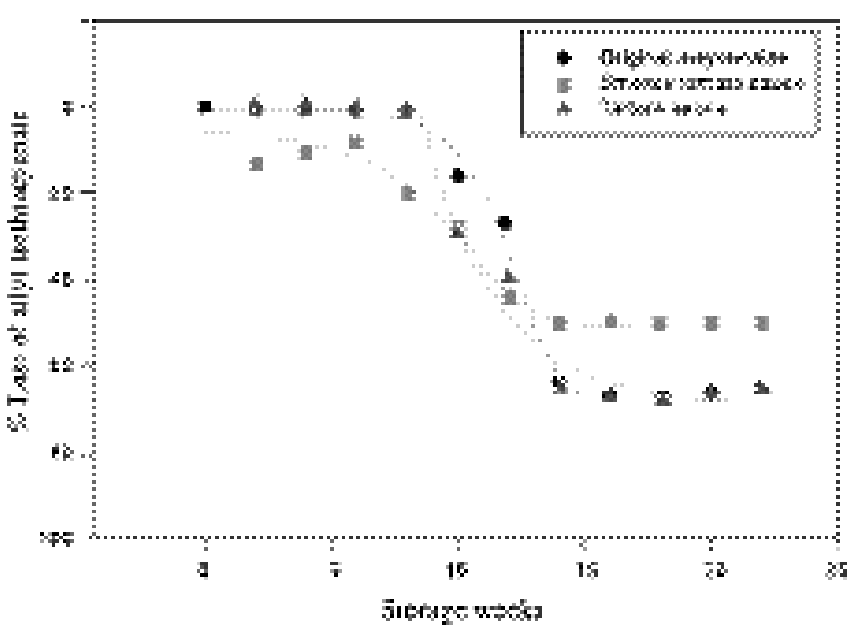

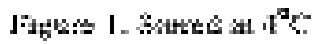

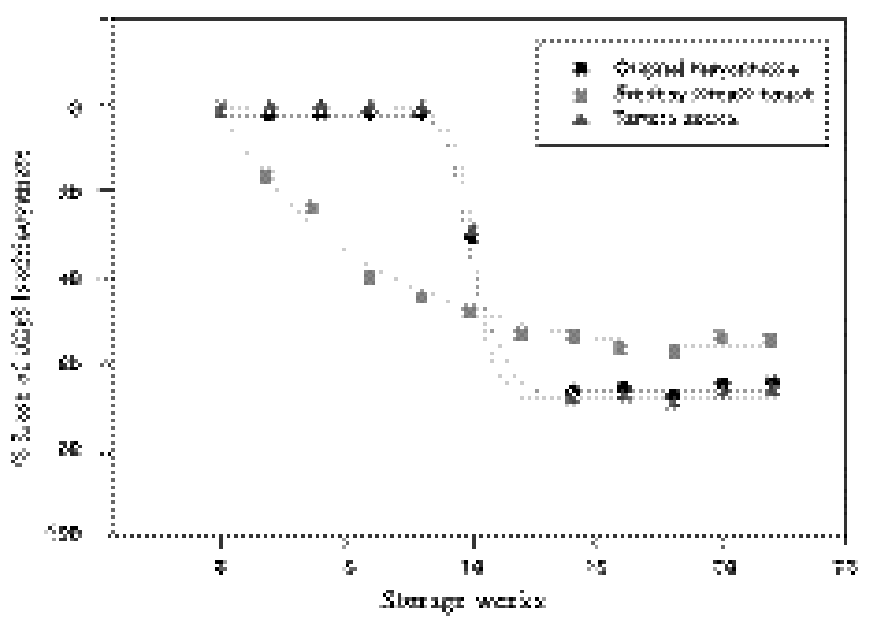

$F: x$ ate 2. 3tox $x d t U^{3} E$

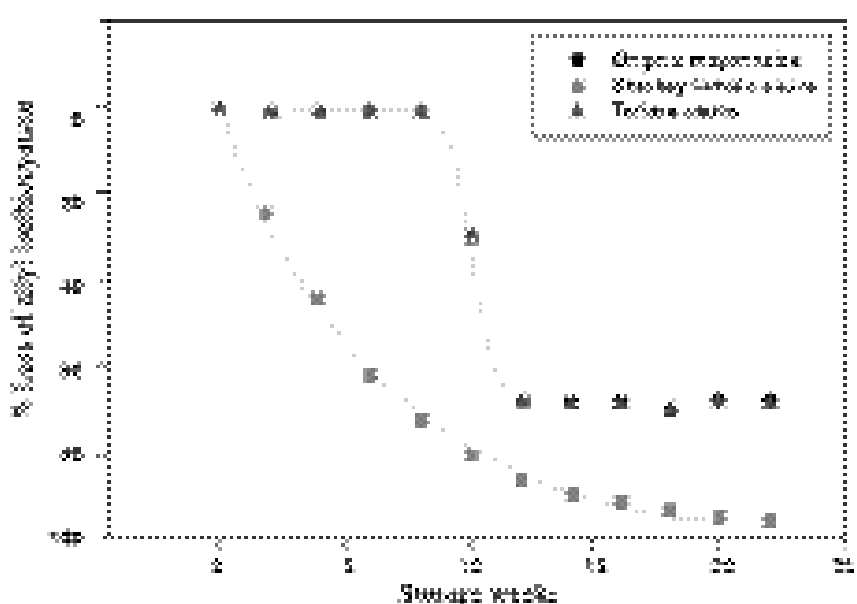

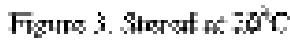

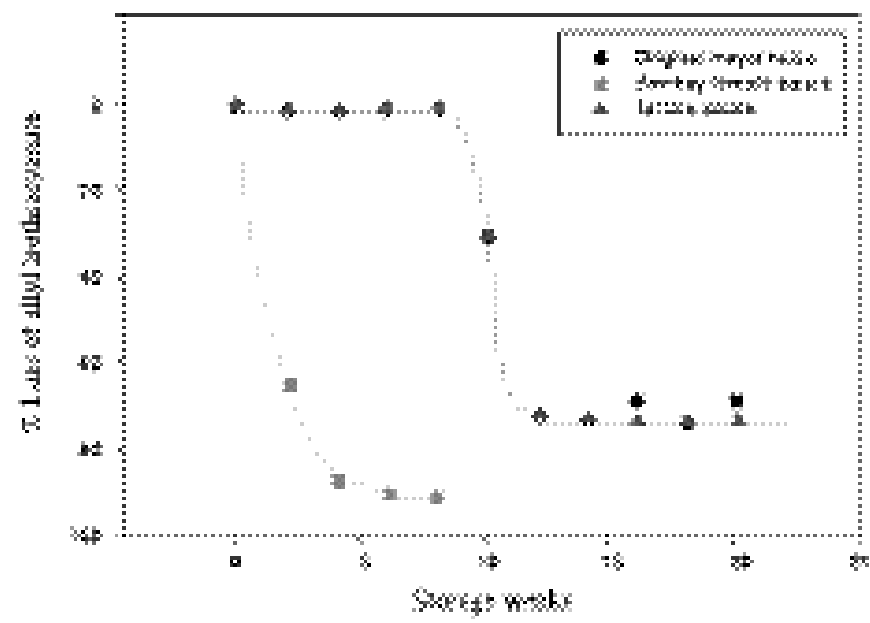

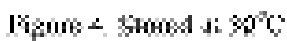

Figure 1-4: The decay pattern of allyl ITC in the three wasabi flavoured sauces when stored at four different temperatures

and the product was spoiled and all allyl ITC was completely lost after 8 weeks (Fig. 4).

The original mayonnaise and tartare sauces, which contained much higher amounts of allyl ITC from manufacture, followed a sigmoidal decay curve. In the decay pattern for the creamy sauces, the \% loss of allyl ITC remained unchanged until 8 weeks (1-2 \% loss) followed by a sudden loss at 10 weeks and then minor losses until the end of 22 weeks. For instance, at $30^{\circ} \mathrm{C}$ storage, the original mayonnaise and tartare sauces showed 2, 31, 69-70\% loss of allyl ITC at 8,
10 and 22 weeks, respectively, compared to the original level at the start of storage period. By comparing storage temperatures, an increasing loss of allyl ITC occurred at higher storage temperatures. For example, the remaining levels of allyl ITC in original mayonnaise at the end 22 weeks were $27 \%$ and $31 \%$ of the original level (from zero day of storage) when stored at $30^{\circ} \mathrm{C}$ and $20^{\circ} \mathrm{C}$ respectively. Similarly, $26 \%$ and $31 \%$ of allyl ITC level investigated in tartare sauce at 22 weeks from $30^{\circ} \mathrm{C}$ and $20^{\circ} \mathrm{C}$ of storage. Whereas, for smoky tomato sauce, at storage 8 weeks, the 
remaining level of allyl ITC found $9.6 \%$ and $27 \%$ of the original level (at zero day of storage) from $30^{\circ} \mathrm{C}$ and $20^{\circ} \mathrm{C}$ of storage respectively.

\section{Statistical support for the fitted lines}

The fit of the non-linear model to the time dependent responses was checked by comparing the graphs of the original observations and the fitted values against time, examining the t-values of the function coefficients and checking the $R_{2}$ values. The graphs showed very good fits, the $R_{2}$ values ranged from a minimum of $94.4 \%$ to $99.9 \%$ with an average of $98.9 \%$.

\section{Effects of sauces types}

Among the three sauces, the creamy sauces gave significantly different coefficients in the fitted curve (m, c, b and a) compared to the non-creamy sauce (Table II). But no significant difference for coefficients of fitted curve found between the two creamy sauces, i.e. the original mayonnaise and the tartare sauce. For example, the inflexion point (m) in the logistic curve of smoky tomato sauce was 5.06 but for creamy sauces it was between 10.34 and 10.63. Obviously the decline of allyl ITC in smoky tomato sauce started quickly with respect to storage time (Fig. 2-4) and deterioration proceeded rapidly. In addi- tion, the lower asymptote (a) in the logistic curve was much lower (38.6) for the smoky tomato than the other two sauces (125 - 131) (Table IV), which indicates a greater loss of allyl ITC in the smoky tomato sauce. However, the total amount of reduction (c) in

Table II. The effect of sauces on the coefficient of the fitted curve

\begin{tabular}{|c|c|c|c|c|c|}
\hline \multirow{3}{*}{$\begin{array}{c}\text { Co- } \\
\text { efficient } \\
\text { of the } \\
\text { fitted } \\
\text { curve }\end{array}$} & \multicolumn{3}{|c|}{ Wasabi flavoured sauces } & \multirow{3}{*}{$\begin{array}{l}\text { SE } \\
\mathrm{M}\end{array}$} & \multirow{3}{*}{$\begin{array}{c}P \\
\text { Value }\end{array}$} \\
\hline & \multicolumn{2}{|c|}{ Creamy sauces } & \begin{tabular}{|c|} 
Non \\
creamy \\
sauce \\
\end{tabular} & & \\
\hline & $\begin{array}{c}\text { Ori- } \\
\text { ginal } \\
\text { mayon } \\
\text { naise }\end{array}$ & $\begin{array}{l}\text { Tar- } \\
\text { tare } \\
\text { sauce }\end{array}$ & $\begin{array}{l}\text { Smoky } \\
\text { tomato }\end{array}$ & & \\
\hline b & -1.942 & -1.982 & -0.797 & 0.12 & $<0.001$ \\
\hline $\mathrm{m}$ & 10.63 & 10.34 & 5.06 & 0.20 & $<0.001$ \\
\hline C & 280.7 & 286.7 & 111.5 & 3.2 & $<0.001$ \\
\hline $\mathrm{a}$ & 130.3 & 124.9 & 38.6 & 2.5 & $<0.001$ \\
\hline
\end{tabular}

SEM = Standard error of means allyl ITC was comparatively smaller in smoky tomato (111.5) than the creamy sauces (281-287) because it contained a lower level of allyl ITC when it was initially manufactured.

\section{Effects of temperatures}

The increasing temperature significantly moved the inflexion point (m) earlier in the fitted curve (Table III) indicating

Table III. The effect of storage temperature on the coefficient of the fitted curve

\begin{tabular}{c|c|c|c|c|c|c}
\hline \multirow{2}{*}{$\begin{array}{c}\text { Co- } \\
\text { efficient } \\
\text { of the } \\
\text { fitted }\end{array}$} & \multicolumn{5}{|c|}{ Storage temperatures $\left({ }^{\mathrm{O}} \mathrm{C}\right)$} & \\
\cline { 2 - 6 } curve & 4 & 10 & 20 & 30 & & \\
\hline b & -0.901 & -1.528 & -1.720 & -2.145 & 0.139 & $<0.001$ \\
$\mathrm{~m}$ & 10.88 & 8.32 & 8.24 & 7.26 & 0.23 & $<0.001$ \\
$\mathrm{c}$ & 206.9 & 211.4 & 239.5 & 247.4 & 3.7 & $<0.001$ \\
$\mathrm{a}$ & 112.7 & 114.2 & 86.7 & 78.1 & 2.9 & $<0.001$ \\
\hline
\end{tabular}

that the decline of allyl ITC was influenced by higher temperatures. For instance, the m values were 10.9, 8.3, 8.2 and 7.3 for the storage temperatures of $4,10,20$ and $30^{\circ} \mathrm{C}$, respectively, which showed a linear relationship of ' $m$ ' with storage temperature. Consequently, the deterioration occurred sooner at higher temperatures. Even the level of reduction (c) and the lower asymptote (a) were significantly different $(\mathrm{P}<0.001)$ with increasing temperature from 4 to $30^{\circ} \mathrm{C}$ (Table III). Therefore, temperature was the main treatment that caused the biggest effects during the course of this shelf-life study.

\section{Temperature versus sauces interaction}

Temperature versus sauce interaction showed that temperature had comparatively little effect on creamy sauces (mayonnaise and tartare sauces) but a large effect on the smoky tomato sauce (Table IV). A linear decline noticed from the inflexion point $\mathrm{m}$ and the lower asymptote a of the fitted curve for the smoky tomato showed that it was the most sensitive sauce to temperature and, thus, m was reduced and reached a lower level with increasing temperature in a shorter time. Thus, the higher the temperature the more rapid was the reduction of allyl ITC in the smoky tomato sauce. For example, at $30^{\circ} \mathrm{C}$ the smoky tomato sauce started to deteriorate quickly and loose $90 \%$ of allyl ITC within 4 weeks. Also 
Table IV. Interaction of sauces by temperature on the coefficient of the fitted curve

\begin{tabular}{|c|c|c|c|c|c|c|c|}
\hline \multirow{2}{*}{$\begin{array}{l}\text { Coefficient } \\
\text { of the } \\
\text { fitted curve }\end{array}$} & \multirow{2}{*}{ Sauces } & \multicolumn{4}{|c|}{ Storage temperatures $\left({ }^{\circ} \mathrm{C}\right)$} & \multirow[t]{2}{*}{ SEM } & \multirow[t]{2}{*}{$P$ Value } \\
\hline & & 4 & 10 & 20 & 30 & & \\
\hline $\mathrm{b}$ & Original mayonnaise & -1.31 & -1.86 & -2.30 & -2.30 & 0.24 & 0.016 \\
\hline $\mathrm{b}$ & Tartare & -0.71 & -2.26 & -2.50 & -2.45 & & \\
\hline $\mathrm{b}$ & Smoky tomato & -0.68 & -0.46 & -0.36 & -1.68 & & \\
\hline $\mathrm{m}$ & Original mayonnaise & 12.10 & 10.10 & 10.11 & 10.21 & 0.40 & $<0.001$ \\
\hline $\mathrm{m}$ & Tartare & 10.98 & 10.10 & 10.11 & 10.15 & & \\
\hline $\mathrm{m}$ & Smoky tomato & 9.57 & 4.75 & 4.49 & 1.43 & & \\
\hline c & Original mayonnaise & 273.9 & 270.2 & 283.4 & 295.2 & 6.3 & $<0.001$ \\
\hline c & Tartare & 282.1 & 277.4 & 284.8 & 302.2 & & \\
\hline c & Smoky tomato & 64.5 & $65.0 \dagger$ & $65.0 \dagger$ & $65.0 \dagger$ & & \\
\hline a & Original mayonnaise & 134.5 & 142.4 & 128.8 & 115.7 & 4.9 & $<0.001$ \\
\hline a & Tartare & 133.0 & 133.7 & 125.5 & 107.4 & & \\
\hline $\mathrm{a}$ & Smoky tomato & 70.5 & 66.7 & 5.8 & 11.3 & & \\
\hline
\end{tabular}

$\dagger$ Values fixed for curve fitting, SEM = Standard error of means

the reduction reached a lower level (a) at a higher temperature in all the sauces.

\section{Effect of storage time}

From the logistic curve an estimated shelf life to a 5\% decline in allyl ITC level was calculated. For the creamy sauces the shelf life of 8 and 9 weeks was indicated for the tartare and mayonnaise sauces, respectively, which was unaffected by storage temperatures. However, the smoky tomato sauce was highly influenced by storage temperature and had a very much shorter shelf life at 1.6 weeks.

\section{Colour of the sauces}

The colour of the sauces were expressed using three CIE LAB components L*, a* and $b^{*}$ which explain brightness, red-green component and yellow-blue component in sauces, respectively. On the day of manufacture, the original mayonnaise showed values of $96.08 \pm 0.20\left(\mathrm{~L}^{*}\right), 1.00 \pm 0.02\left(-\mathrm{a}^{*}\right)$ and $14.13 \pm 0.05\left(+\mathrm{b}^{*}\right)$, which explained a light greenishyellow colour that could be seen in this sauce (Table V). In comparison, the tartare sauce was a little darker (88.16 \pm $\left.0.51 \mathrm{~L}^{*}\right)$ with more a greenish $\left(-2.32 \pm 0.003\right.$, $\left.-\mathrm{a}^{*}\right)$ but a little less yellowish $\left(12.88 \pm 0.07,+b^{*}\right)$ in components on zero day of storage. However, smoky tomato was the darkest sauce $\left(47.41 \pm 0.09, L^{*}\right)$ with a mixture of strong reddish
Table V. The mean and SEM of the Chromatic coordinates of the CIE LAB system in the three sauces on the day of manufacture $\left(L^{*}=\right.$ brightness; $a^{*}=$ redgreen component, $b^{*}=$ yellow-blue component)

\begin{tabular}{l|c|c|c}
\hline \multicolumn{1}{c|}{ Sauces } & \multicolumn{3}{|c}{ Co-ordinates of the CIE LAB system } \\
\cline { 2 - 4 } & $\mathrm{L}^{*} \pm$ SEM & $\mathrm{a}^{*} \pm$ SEM & $\mathrm{b}^{*} \pm$ SEM \\
\hline $\begin{array}{l}\text { Original } \\
\text { mayonnaise }\end{array}$ & $96.08 \pm 0.20$ & $-1.00 \pm 0.02$ & $14.13 \pm 0.05$ \\
$\begin{array}{l}\text { Tartare } \\
\text { sauce }\end{array}$ & $88.16 \pm 0.51$ & $-2.32 \pm 0.003$ & $12.88 \pm 0.07$ \\
$\begin{array}{l}\text { Smoky } \\
\text { tomato }\end{array}$ & $47.41 \pm 0.09$ & $+35.46 \pm 0.05$ & $36.88 \pm 0.29$ \\
\hline
\end{tabular}

SEM $=$ Standard error of means

$\left(35.46 \pm 0.05,+\mathrm{a}^{*}\right)$ and yellow $\left(36.88 \pm 0.29,+\mathrm{b}^{*}\right)$ in the observed colour. When the sauces in the two types of packets were compared a slight increase of a* $(0.4-1.8)$, $\mathrm{L}^{*}$ values (2-6) but a decrease in $b^{*}$ value (1.5-3) was noticed in the mayonnaise stored in the metallic pouches at $30^{\circ} \mathrm{C}$. This was observed from storage 8 weeks onwards. Similarly, the tartare sauces contained in the metallic coloured pouches showed an increase in $\mathrm{a}^{*}(0.8-2.0), \mathrm{L}^{*}$ values $(2-5)$ but decreased the $\mathrm{b}^{*}$ value $(0.5-2)$ at $30^{\circ} \mathrm{C}$ storage from 8 weeks onwards. However, no differences in $\mathrm{L}^{*}, \mathrm{a}^{*}$ and $\mathrm{b}^{*}$ values were noticed in the smoky tomato sauce stored at $30^{\circ} \mathrm{C}$ until 
8 weeks. Otherwise, temperature and time had no significant effect in changing the colour of sauces in this study.

The overall flavour of a sauce is derived from a combination of all the ingredients (oil, vinegar, egg yolk, sugar and spices) present in it. In this study the main flavour component used in the sauces was allyl ITC. A shorter shelf-life and a different decay pattern was observed for allyl ITC (at = $10^{\circ} \mathrm{C}$ storage) in the smoky tomato sauce when compared to the original mayonnaise and tartare sauces in this study. Thus, a difference in allyl ITC behaviour was identified during the shelf-life study of different wasabi sauces. The smoky tomato sauce was a non-creamy sauce and was different from the original mayonnaise and tartare sauces, which were traditional creamy sauces. The smoky tomato sauce also contained $4.6 \%$ less "wasabi oil" and much lower total fat content (7\%) compared to the creamy sauces $(28-30 \%$ total fat). However, the smoky tomato sauce contained 8-9\% more water than creamy sauces. This non-creamy sauce was based on tomato paste and was the only sauce that was heattreated at $100^{\circ} \mathrm{C}$ for 30 minutes once it had been sealed in the pouches. This heat treatment was carried out to sterilize the ingredients, which could have been microbiologically contaminated during preparation. The heating process resulted in a $16 \%$ instant reduction in allyl ITC level in the sauce. Reports from previous researches suggests that due to the volatile nature of ITCs the loss of ITC increases at higher temperatures $\left(=100^{\circ} \mathrm{C}\right)$ with increasing time period involved in processing and storage of foods, mainly due to evaporation loss (Chen and Ho, 1998; Yong-Gang et al., 1994; Hekiyama et al., 1994). Between $10-65^{\circ} \mathrm{C}$ the loss of ITCs is rather complex, it depends on the presence of other substances in raw or finished foods and ITCs reacts with other substances and gradually degrades or converts to other chemical compounds (Chen and Co, 1998; Bierheilig and Ocampo, 1990; Kojima et al., 1982) which may be another way of ITC reduction in addition to evaporation loss. For instance, synthetic allyl ITC was found unstable in the presence of water at $37^{\circ} \mathrm{C}$ and it gradually degrades to a nonvolatile compound, N, N-diallyl-thiourea (Chen and Ho, 1998). Similarly, Depree and Savage (1996) highlighted that water is an important concern for retaining the original level of ITCs in mayonnaise since ITCs decreased in stored mayonnaise (prepared with 'wasabi oil') with time whereas 99\% of the original level of ITCs was found in the same 'wasabi oil' after 57 days of storage at $4^{\mathrm{O}} \mathrm{C}$. Thus, lowering the amount of active water in a sauce could be an important issue to increase the shelf life of allyl ITC. In agreement with this, it seems that, difference in water contained between creamy and non-creamy sauces may also have played a role in the present study giving a different decay pattern of allyl ITC when stored at $10^{\circ} \mathrm{C}$ or higher temperatures.

Temperature was found to be an important factor linked to the falling allyl ITC levels in sauces during storage. Specifically, when the smoky sauces were stored at a higher temperature the shelf life of the sauces was reduced and the allyl ITC levels reduced markedly. For creamy sauces, the higher the temperature also showed a trend of more reduction of allyl ITC and, therefore, agrees with an earlier study (Depree and Savage, 1996), which showed a trend of lower reduction of ITCs (15\%) in mayonnaise when stored at 4 to $20^{\circ} \mathrm{C}$ but increased reduction (25\%) when stored at elevated temperature $\left(30^{\mathrm{O}} \mathrm{C}\right)$.

No microbiological growth was observed in any of the samples during the entire study (Jonathan Depree, Pers. Com) even when the sauces were stored at $30^{\circ} \mathrm{C}$. In an earlier report (Depree and Savage, 2001), it was noted that due to the low $\mathrm{pH}$ and high fat content of the creamy sauce was relatively resistant to microbiological spoilage. But, ITCs are known to act as an inhibitor of food poisoning bacteria and have antibiotic and fungicidal properties (Ono et al., 1998; Brown and Morra, 1997; Hasegawa et al., 1999; Nakayama et al., 1998; Shin and Lee, 1998 ). Consequently, it seems that allyl ITCs might have had an inhibitory role on the growth of micro-organisms in these sauces, which needs to be investigated further.

\section{Conclusion}

Mayonnaise and tartare sauces made with 11\% "wasabi oil" can be stored for up to 8 weeks at any temperature up to $30^{\circ} \mathrm{C}$. In contrast, the smoky tomato sauce, which contained a lower level of "wasabi oil" (6.4\%), was very unstable even when stored at $4^{\mathrm{O}} \mathrm{C}$. The water to oil ratio is also important for the long term stability of allyl ITC in these types of sauces.

\section{Acknowledgements}

We wish to thank Mr. M. Kitson of Jatra Corporation Ltd. for financial support in this work. We thankfully acknowledge Mr. Bruce Clark, University of Canterbury, New Zealand for his assistance with GCMS analysis of individual isothiocyanates in wasabi-flavoured sauces. 


\section{References}

Brown P. D., and Morra M. J. (1997) Control of soil-borne plant pests using glucosinolate-containing plants. Advanced Agronomy, 61: 167-231.

Chen C. W., and Ho C. T. (1998) Thermal degradation of Allyl ITC in Aqueous solution. Journal of Agriculture and Food Chemistry, 46: 220-223.

Depree J. A., and Savage G. P. (1996) Storage properties of a wasabi flavoured mayonnaise. Proceedings of the Nutrition Society of New Zealand, 21: 142-151.

Depree J. A., and Savage G. P. (2001) Physical and flavour stability of mayonnaise. Trends in Food Science and Technology, 12: 157-163.

Genstat (2000) Genstat release 4.2 reference manual, Genstat committee, Lawes Agricultural Trust, Harpenden, Hertfordshire, UK.

Hasegawa N., Matsumoto Y., Hoshino A., and Iwashita K. (1999) Comparison of effects of Wasabia japonica and allyl isothiocyanate on the growth of four strains of vibrio parahaemolyticus in lean and fatty tuna meal suspension. International Journal of Food Microbiology, 49: 27-34.

Masuda H., Harada Y., Tanaka K., Nakajima M., Tebeta H., Takeoka G. R., Teranishi R., Williams P. J., and Kobayash I. A. (1996) Characteristic odorants of wasabi (Wasabia japonica Matum) (Eutrema wasabi), Japanese horseradish, in comparison with those of horseradish (Armoracia rusticana). Biotechnology for Improved Foods and Flavours. ACS Symposium Series No. 637, 25: 67-78.

Nakayama H., Suzuki T., and Suzuki Y. (1998) Effect of wasabi on ion secretion in guinea pig colon. Nippon Nogeikagaku Kaishi, 72: 499-507.

Ono H., Tesaki S., Tanabe S., and Watanabe M. (1998) 6Methylsulphinylhexyl isothiocyanate and its homologues as food-originated compounds with antibacterial activity against Escherichia coli and Staphylococcus aureus. Bioscience Biotechnology and Biochemistry, 62(2): 363-365.
Kjoer A., Ohashi M., Wilson J. M., and Djerassi C. (1963) Mass spectra of isothiocyanates. Acta Chemica Scandinavica, 17: 2143-2154.

Kojima M., and Nakano Y. (1980) Studies on evaluation of quality of Japanese horseradish (wasabi) powder by gas chromatography. X. Studies to change in pungent components during storage of horseradish, mustard and wasabi powder. Journal of Japanese Society of Food Science and Technology, 27(2): 86-88.

Kojima M., Hamada H., and Yamashita M. (1982) Studies on the evaluation of quality of Japanese horseradish (wasabi) powder by gas chromatography. XI. Studies on the stability of dried wasabi flour. Japanese Society of Food Science and Technology, 29(4): 232-237.

Sahasrabudhe M. R., and Mullin W. J. (1980) Dehydration of horseradish roots. Journal of Food Scienc, 45: 14401443.

Sekiyama Y., Mizukami Y., Takada A., and Numata S. (1994) Vapour pressure and stability of allyl isothiocyanate. Journal of the Food Hygienic Society of Japan, 35(4): 365-370.

Shin I. S., and Lee J. M. (1998) Study on antimicrobial and antimutagenic activity of horseradish (Wasabia japonica) root extracts. Bulletin of Korean Ficheries Society, 31: 835-184.

Sigmaplot. (1999). Sigmaplot Version 5.0, SPSS Inc., Canal Blvd. Suite F, Richmond, USA.

Sultana T., Savage G. P., McNeil D. L., Porter N., Martin R. J., and Deo B. (2002) Effects of fertilisation on the allyl isothiocyanate profile of the above-ground tissues in New Zealand grown wasabi. Journal of the Science of Food and Agriculture, 82: 1477-1482.

Sultana T., Savage G. P., McNeil D. L., Porter N. G., and Clark B. (2003) Comparison of flavour compounds in wasabi and horseradish. Journal of Food Agriculture \& Environment, 1(2): 117-121.

Sultana T., Savage G. P., McNeil D. L., Porter N., and Martin R. J. (2000) Flavour compounds in the rhizome of soilgrown wasabi. Proceedings of the Nutrition Society of New Zealand, 25: 95-106. 
Tseng C. Y., Tsai T. C., and Tseng Y. K. (1986) Studies on the processing of wasabi produced in Taiwan. I. Production of wasabi powder. Food Science,China, 13(1/2): 60-70.

Vierheilig H., and Ocampo, J. A. (1990). Effect of isothiocyanates on germination of spores of G. mosseae. Soil Biology and Biochemistry, 28(8): 1161-1662.
Yong-Gang L., Steg A., Smits B., and Tamminga S. (1994) Crambe meal: removal of glucosinolates by heating with additives and water extraction. Animal Feed Science and Technology, 48(3-4): 273-287.

Received : August, 12, 2008;

Accepted : November 06, 2008 